\title{
Tuning the Emission Colour of Europium-containing Ionic Liquid-crystalline Phases
}

Erwann Guillet, Daniel Imbert, Rosario Scopelliti, Jean-Claude G. Bünzli

Swiss Federal Institute of Technology, Lausanne, Laboratory of Lanthanide Supramolecular Chemistry, BCH 1402, CH-1005 Lausanne, Switzerland

\section{Supplementary Material \\ 3 pages}

Table S1. Analytical data for anhydrous $\left[\mathrm{C}_{12}-\mathrm{mim}\right] \mathrm{NO}_{3},\left[\mathrm{C}_{14}-\right.$ $\operatorname{mim}] \mathrm{NO}_{3},\left[\mathrm{C}_{16}-\mathrm{mim}\right] \mathrm{NO}_{3}$ and $\left[\mathrm{C}_{18}-\mathrm{mim}\right] \mathrm{NO}_{3}$. Found (calcd).

\begin{tabular}{cccc}
\hline & $\mathrm{C}$ & $\mathrm{H}$ & $\mathrm{N}$ \\
\hline 12 & $61.6(61.3)$ & $10.0(10.0)$ & $13.64(13.4)$ \\
14 & $63.6(63.3)$ & $10.1(10.3)$ & $12.23(12.3)$ \\
16 & $64.8(65.0)$ & $10.7(10.6)$ & $11.42(11.4)$ \\
18 & $66.3(66.2)$ & $11.2(10.9)$ & $10.47(10.6)$ \\
\hline
\end{tabular}

Table S2. Crystal field splitting in N5 and $\mathbf{C 5}$ as determined from high resolution luminescence spectra at $10 \mathrm{~K}\left(\mathrm{in} \mathrm{cm}^{-1}\right)$. The origin is taken as the ${ }^{7} \mathrm{~F}_{0}$ level.

\begin{tabular}{lll}
\hline Transition & C5 & N5 \\
\hline${ }^{5} \mathrm{D}_{0} \rightarrow{ }^{7} \mathrm{~F}_{1}$ & 346 & 365 \\
& 378 & 386 \\
& 403 & 403 \\
\hline${ }^{5} \mathrm{D}_{0} \rightarrow{ }^{7} \mathrm{~F}_{2}$ & 888 & 893 \\
& 913 & 909 \\
& & 958 \\
& 990 & 1006 \\
& & 1056 \\
& 1077 & 1078 \\
& 1108 & 1108 \\
& 1135 & \\
\hline
\end{tabular}

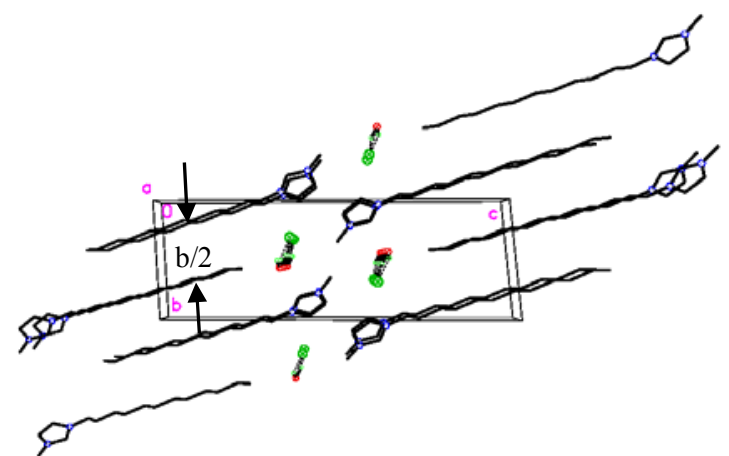

Figure S1. Projection of the X-ray structure of $\left[\mathrm{C}_{12}-\mathrm{mim}\right] \mathrm{Cl} \cdot \mathrm{H}_{2} \mathrm{O}$ on the (bc) plane showing the interdigitation of the alkyl chains; hydrogen atoms omitted for clarity.

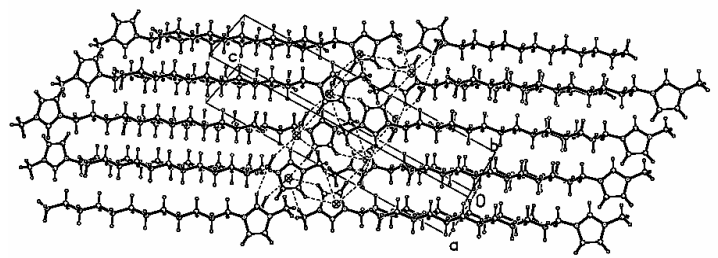

Figure S2. Packing of the $\left[\mathrm{C}_{12}-\mathrm{mim}\right] \mathrm{Cl} \cdot \mathrm{H}_{2} \mathrm{O}$ structure

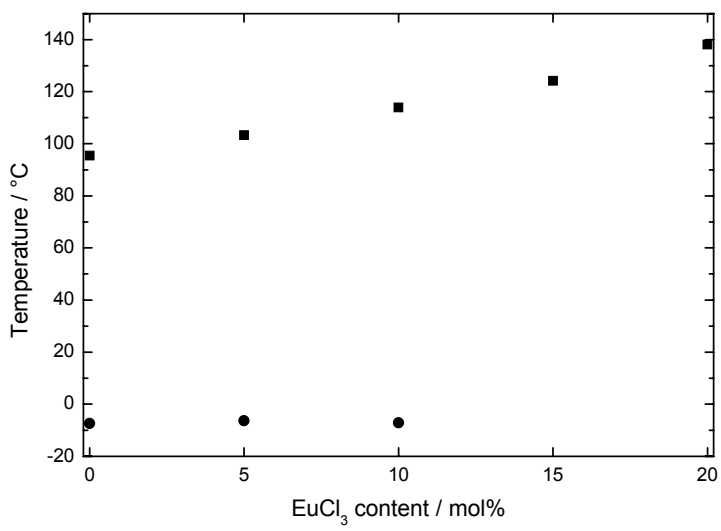

Figure S3. Dependence of the transition temperatures $(\bullet: \mathrm{Cr}-\mathrm{LC}, \boldsymbol{\bullet}$ $\mathrm{LC}-\mathrm{I})$ of $\left[\mathrm{C}_{12}\right.$-mim $] \mathrm{Cl}$ on the $\mathrm{EuCl}_{3}$ content.

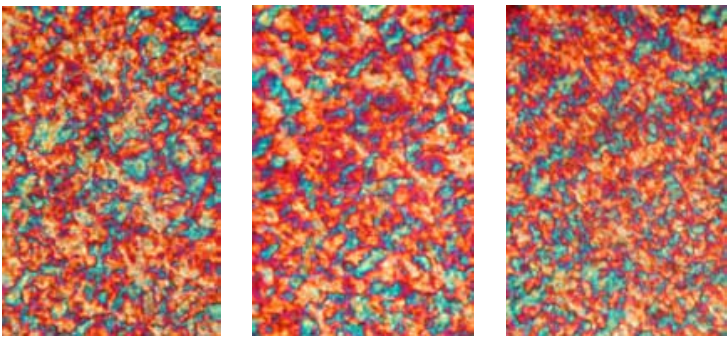

Figure S4. Polarised luminescence microscopy of $\left[\mathrm{C}_{12}-\mathrm{mim}\right] \mathrm{Cl}, \mathrm{C} 10$ and $\mathrm{P} 10$ at $80{ }^{\circ} \mathrm{C}$

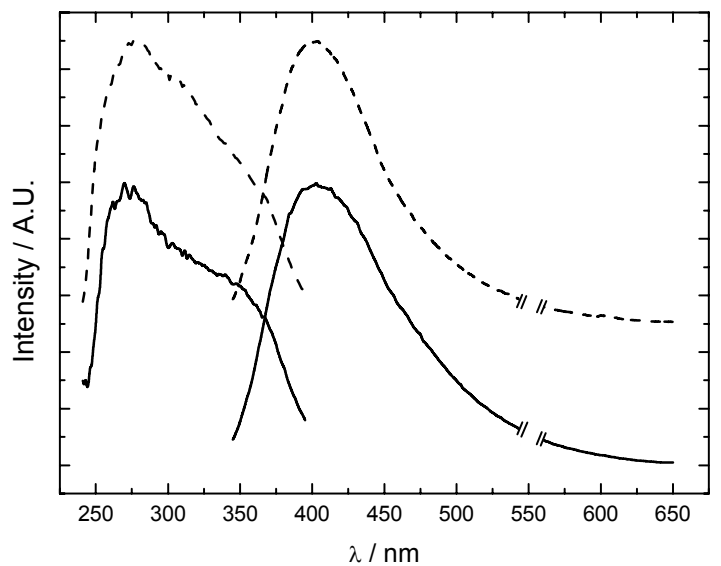

Figure S5. Normalized excitation (left) and emission (right) spectra of pure $\left[\mathrm{C}_{12}-\mathrm{mim}\right] \mathrm{Cl}$ (line) and a solution $1 \mathrm{M}$ in dichloromethane (dash). Rayleigh bands suppressed. 


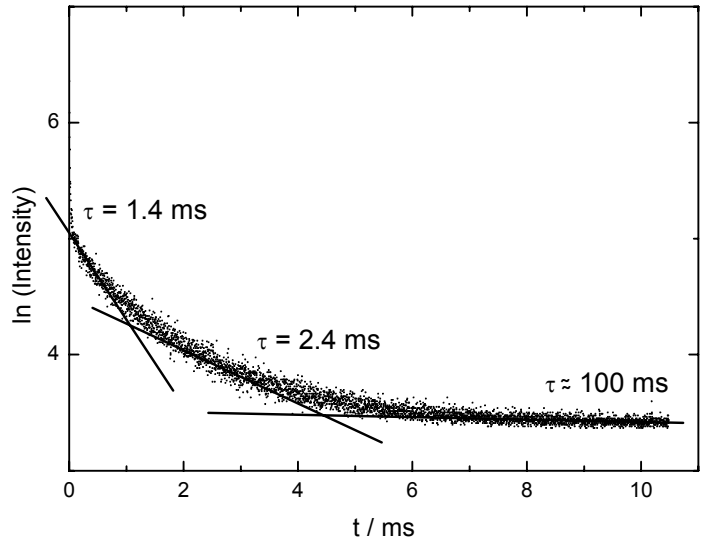

Figure S6. Logarithmic plot of $\ln \left(\right.$ emission) versus the time for $\left[\mathrm{C}_{12}\right.$ $\operatorname{mim}] \mathrm{Cl}$ at $295 \mathrm{~K}$ monitored at $612 \mathrm{~nm}$ under excitation at $355 \mathrm{~nm}$, showing the non-exponential decay. Several trend lines can be fitted to the curve and the long-lived emission has an approximate lifetime of $100 \mathrm{~ms}$.

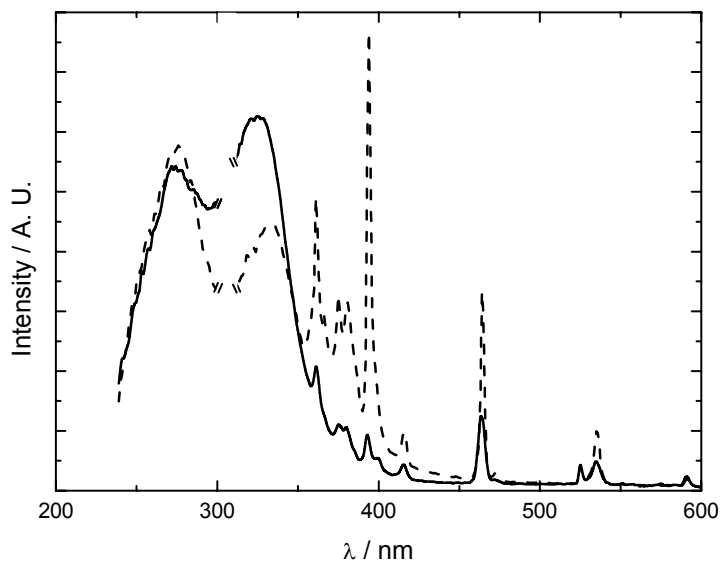

Figure S7. Excitation spectra of C5 (line, monitored at $611 \mathrm{~nm}$ ) and of $\mathbf{N 5}$ (dash, monitored at $617 \mathrm{~nm}$ ), at room temperature in the mesogenic state.

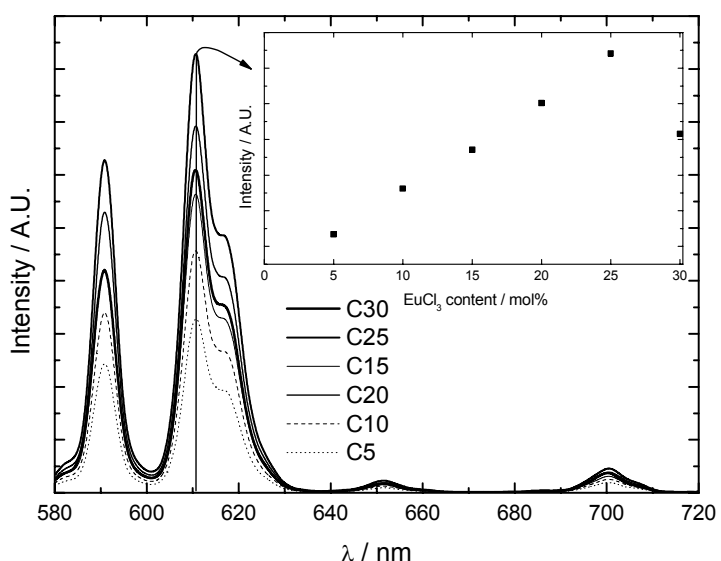

Figure S8. Phosphorescent emission spectra (delay $0.01 \mathrm{~ms}$ ) by excitation at $355 \mathrm{~nm}$, recorded at room temperature under mesogenic state, of $\mathbf{L C}$ doped with increasing quantities of $\mathrm{EuCl}_{3}$, from $5 \mathrm{~mol} \%$ to $30 \mathrm{~mol} \%$.

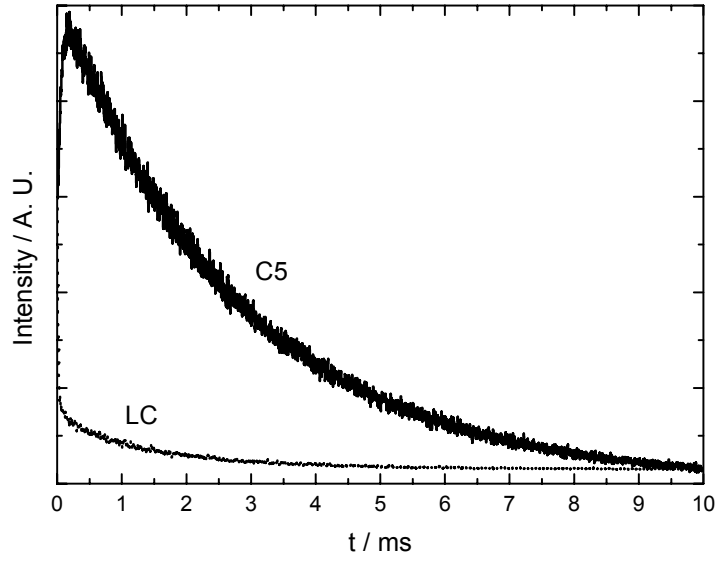

Figure S9. Luminescence decays of $\left[\mathrm{C}_{12}-\mathrm{mim}\right] \mathrm{Cl}$ and $\mathbf{C 5}$ at room temperature, recorded under excitation at $355 \mathrm{~nm}$, and observed at $612 \mathrm{~nm}$.

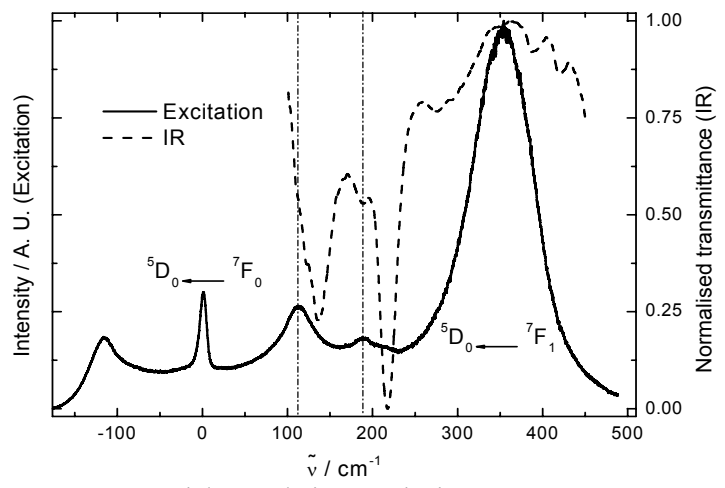

Figure S10. High resolution excitation spectrum at $295 \mathrm{~K}$ (monitored at $612.25 \mathrm{~nm}$ ) and IR spectrum of C5; the origin of the excitation spectrum is set on the ${ }^{5} \mathrm{D}_{0} \leftarrow{ }^{7} \mathrm{~F}_{0}$ band.

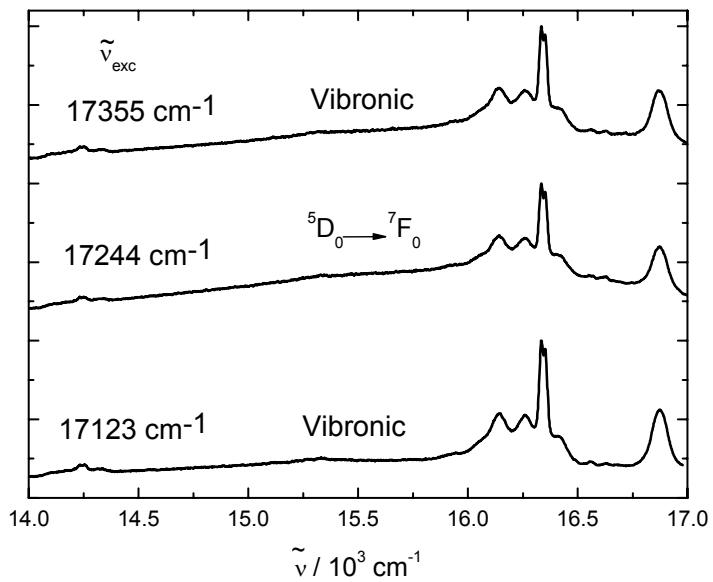

Figure S11. High resolution emission spectra at $295 \mathrm{~K}$ by excitation on the ${ }^{5} \mathrm{D}_{0} \leftarrow{ }^{7} \mathrm{~F}_{0}$ state (line) and on its vibronic components (dot) 


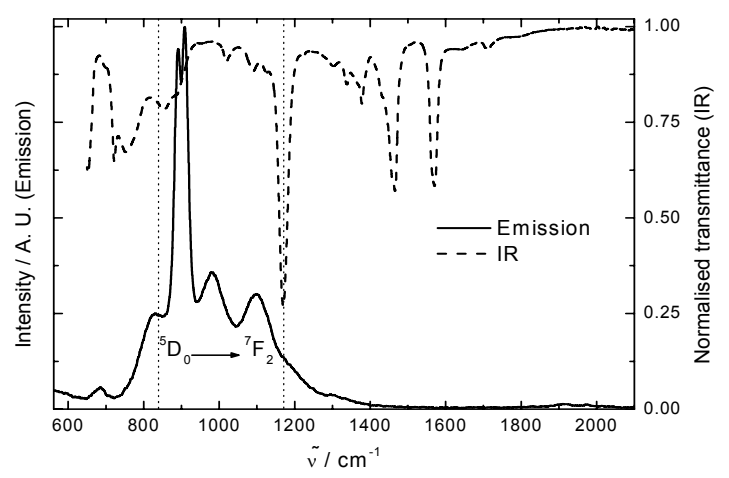

Figure S12. High resolution emission spectrum $\left(\lambda_{\mathrm{ex}}=465.8 \mathrm{~nm}\right)$ and infrared spectrum of $\mathbf{C 5}$ at $295 \mathrm{~K}$; the origin of the spectrum is set on the ${ }^{5} \mathrm{D}_{0} \rightarrow{ }^{7} \mathrm{~F}_{0}$ band.

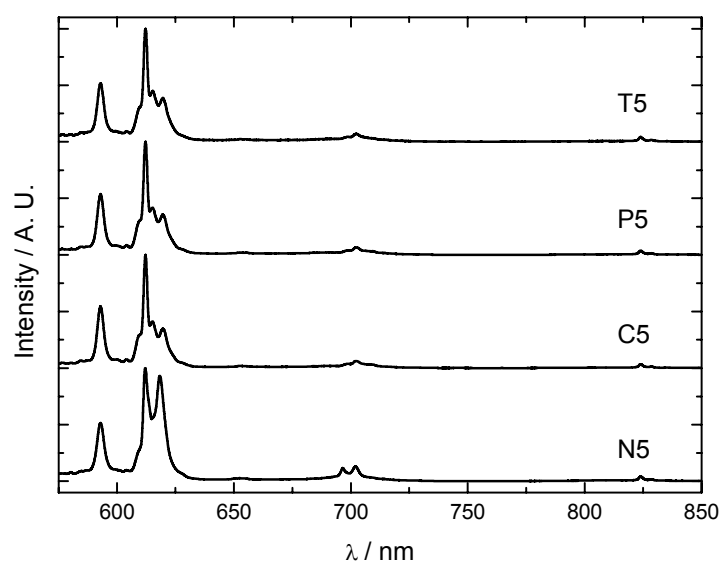

Figure S13. High resolution emission spectra obtained at room temperature for the mesogenic phases $\mathbf{C 5}, \mathbf{N 5}, \mathbf{P 5}$ and $\mathbf{T 5}$ upon broad band excitation at $335 \mathrm{~nm}$. 